\title{
Tendon Transfer for Foot Drop: A Simple Procedure with Effective Outcome Local Experience
}

\author{
Hesham El Sobky, Nabil Ali, Amr Farid Khalil* \\ Department of Neurosurgery, Mansoura University, Mansoura, Egypt \\ Email: ^dr_amr77@yahoo.com
}

How to cite this paper: El Sobky, H., Ali, N. and Khalil, A.F. (2019) Tendon Transfer for Foot Drop: A Simple Procedure with Effective Outcome Local Experience. Open Journal of Modern Neurosurgery, 9, 258-268. https://doi.org/10.4236/ojmn.2019.93025

Received: May 15, 2019

Accepted: June 3, 2019

Published: June 6, 2019

Copyright $\odot 2019$ by author(s) and Scientific Research Publishing Inc. This work is licensed under the Creative Commons Attribution International License (CC BY 4.0).

http://creativecommons.org/licenses/by/4.0/

\section{(c) (i) Open Access}

\begin{abstract}
Introduction: Patients presented with old neglected common peroneal nerve injuries, failed 2ry repair, compression neuropathies not improved after decompression and closed injuries with no improvement on conservative measures which are still unsolved problems. Poor recovery of this nerve after repair or decompression gives great importance to tendon transfer in these situations. Material and Methods: This study was conducted in Neurosurgery Department of Mansoura University from 2015 to 2018 on twenty-six patients (16 males and 10 females). Their age ranged from 6 - 58 years. All of them presented with persistent foot drop at least for one year after injury with no signs of improvement clinically or in electrophysiological studies. All patients underwent tibialis posterior tendon transfer through the interosseous membrane to the tendons of the leg anterior compartment. All of them were put in a plaster cast for four weeks postoperative. A physiotherapeutic program was applied for all patients as preoperative preparation and postoperative rehabilitation. Results: Twenty-two patients showed satisfactory results, three patients fair improvement and one patient no improvement. Two patients had wound infection and there was no mortality in this study. Conclusion: Tendon transfer is an effective valid solution to be considered in the management of foot drop in these patients.
\end{abstract}

\section{Keywords}

Foot, Drop, Tibialis Posterior, Transfer

\section{Introduction}

Common peroneal nerve (CPN) palsy has been reported to be the most frequent lower extremity palsy. CPN injury can be induced by many causes including 
complex leg fractures, sharp or blunt trauma, lacerations, severe knee adduction, or knee dislocation. Moreover, iatrogenic injuries are also reported during removal of ganglion or benign tumours [1] [2].

Many cases of CPN injury can resolve spontaneously. However, irreversible nerve damage can occur despite nerve repair or grafting [3]. The unopposed action of the tibialis posterior muscle results in the characteristic supinated equinovarus deformity. Additionally, foot and finger drop occur resulting in gait disturbance [4] [5].

The process of nerve regeneration is considered to be very poor when it comes to the CPN [6]. Several factors have been incriminated including the long nerve course and excessive connective tissue abundance [2].

Some of these peroneal nerve injuries do not recover at all and may lead to permanent neurological deficits although recent microsurgery developments and greater experience gained from nerve repair have led to increased success rate [7].

An ankle foot orthosis may be helpful in many cases, but patients who have equinovarus contractures, or who have young age show poor tolerance to such way of management. Nowadays, dynamic tendon transposition is considered the gold standard in the management of irreparable CPN paralysis [8].

There are multiple operative solutions that have been described to treat foot drop, but they are all imperfect because of its complexity, or its resort to a bony procedure that may lead to post-operative complications [9].

Back in 1899, Codivilla described the first surgical operation of tendon transfer [10]. After 35 years, Ober managed to transfer the tendon of tibialis posterior muscle onto the anterior tarsus [11]. However, depending on the tarsus as a bony element was a cause of failure [12] [13] [14].

As an alternative to tendon-to-bone suturing, a new method of tendon-to-tendon suturing has been described. The advantages of such method are that it eliminated the need for staples, screws, and wires that are needed for tendon-to-bone fixation and thus, increases the success rate of the procedure [14] [15].

In this study, we describe our technique of tibialis posterior tendon transfer, that was performed in a series of patients who had persistent drop foot due to irreparable CPN injuries.

\section{Patient and Methods}

\subsection{Study Design}

This is a retrospective study of patients presented with persistent foot drop due to common peroneal nerve injury who presented at Mansoura University Hospitals neurosurgical clinics from 2015 to 2018. The study was approved and accepted by the local ethical committee.

\subsection{Patient Sample}

Twenty-six patients $(n=26)$ with persistent foot drop at least one year after 
common peroneal nerve injury were included in our study. These cases did not show any significant improvement on clinical examination or electrophysiological studies. The demographic data of these patients is summarized in Table 1.

\subsection{Inclusion Criteria}

1) Intact plantar dorsiflexion with strong tibialis posterior muscle.

2) Adequate possible passive ankle dorsiflexion.

3) Cases of pure traumatic common peronial nerve injury.

\subsection{Exclusion Criteria}

1) Severely deformed foot.

2) Cases of spontaneous neuropathy.

3) Associated sciatic or posterior tibial nerve injuries.

4) Weak tibialis posterior muscle.

Table 1. Demographic data of the patients.

\begin{tabular}{|c|c|c|c|c|c|}
\hline & Age & sex & side & Trauma & Previous surgery \\
\hline 1 & $18 \mathrm{y}$ & $\mathrm{M}$ & Right & sharp & Yes \\
\hline 2 & $47 y$ & $\mathrm{M}$ & Left & sharp & Yes \\
\hline 3 & $53 \mathrm{y}$ & $\mathrm{F}$ & Right & Knee trauma & No \\
\hline 4 & $44 y$ & $\mathrm{M}$ & Left & Blunt & No \\
\hline 5 & $42 y$ & $\mathrm{M}$ & Right & sharp & Yes \\
\hline 6 & $36 y$ & F & Left & Iatrogenic & Yes \\
\hline 7 & $55 \mathrm{y}$ & $\mathrm{F}$ & Left & Bony fracture & No \\
\hline 8 & $6 y$ & $\mathrm{~F}$ & Right & sharp & Yes \\
\hline 9 & $57 \mathrm{y}$ & $\mathrm{M}$ & Left & Blunt & Yes \\
\hline 10 & $51 \mathrm{y}$ & $\mathrm{M}$ & Left & Blunt & No \\
\hline 11 & $38 \mathrm{y}$ & $\mathrm{M}$ & Left & sharp & Yes \\
\hline 12 & $48 \mathrm{y}$ & $\mathrm{F}$ & Right & Blunt & No \\
\hline 13 & $46 y$ & F & Left & Knee trauma & No \\
\hline 14 & $40 y$ & $\mathrm{M}$ & Right & Nerve tumor & Yes \\
\hline 15 & $37 y$ & $\mathrm{~F}$ & Right & sharp & Yes \\
\hline 16 & $29 y$ & $\mathrm{M}$ & Left & sharp & Yes \\
\hline 17 & $40 y$ & $\mathrm{M}$ & Left & Iatrogenic & Yes \\
\hline 18 & $44 y$ & $\mathrm{M}$ & Right & Blunt & No \\
\hline 19 & $18 \mathrm{y}$ & $\mathrm{M}$ & Left & sharp & Yes \\
\hline 20 & $58 \mathrm{y}$ & F & Right & Knee trauma & Yes \\
\hline 21 & $44 \mathrm{y}$ & $\mathrm{M}$ & Left & sharp & Yes \\
\hline 22 & $37 y$ & $\mathrm{M}$ & Right & Blunt & No \\
\hline 23 & $39 y$ & F & Left & sharp & Yes \\
\hline 24 & $22 \mathrm{y}$ & $\mathrm{M}$ & Left & Knee trauma & No \\
\hline 25 & $48 \mathrm{y}$ & $\mathrm{M}$ & Right & sharp & Yes \\
\hline 26 & $56 y$ & F & Right & Blunt & yes \\
\hline
\end{tabular}




\subsection{Patient Consent}

A written formal consent was obtained from patients after the explanation of the details, advantages and drawbacks of the surgical procedure.

\subsection{Pre-Operative Preparation}

A physiotherapeutic program was applied for all patients as a preoperative lengthening of tendon Achilles to improve passive dorsi flexion. Additionally, patients were trained to use the tibialis posterior muscle.

\subsection{Surgical Procedure}

First of all, all patients were placed in supine position. General or spinal anesthesia was used according to the case. All patients underwent transfer of tibialis posterior tendon to tibialis anterior, extensor hallucis longus, and extensor digitorum tendons.

Three incisions were made as shown in Figure 1; $1^{\text {st }}$ on the medial aspect of the leg above the medial malleolus to harvest the tendon of tibialis posterior, $2^{\text {nd }}$ on the medial aspect of the foot at the base of metatarsal bone to identify the tendon of the tibialis posterior and cut it at its insertion then the tendon is pulled out through the $1^{\text {st }}$ incision as shown in Figure 2. After this, another curvilinear incision was made at the anterior aspect of the lower part of the foot to expose the interosseous membrane and tendons of the muscles of the anterior compartment of the leg.

A small incision of the interosseous membrane and dissector was passed close to the posterior surface of the tibia to the $1^{\text {st }}$ incision and the tibialis posterior tendon was taken through this tunnel anteriorly. After that, we exposed the tendons of the extensor halluces longus, the extensor digitorum and the tibialis anterior. The three tendons are sutured together and shortened to correct their laxity using proline suture then the ligament of the tibialis posterior muscle was sutured to these three tendons as shown in Figure 3. Finally, anatomical closure was done over a drain.

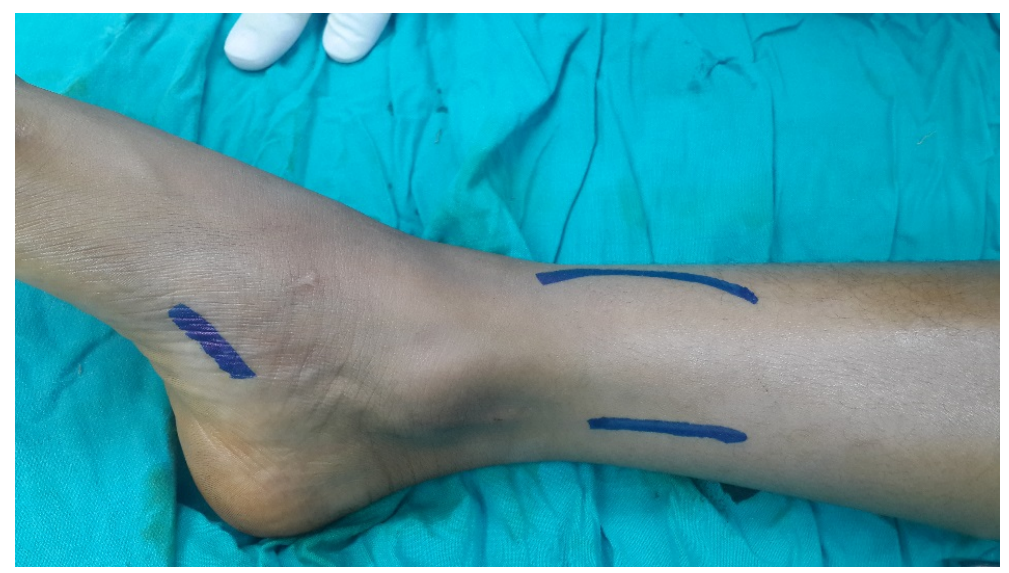

Figure 1. Marking the site of three skin incisions. 


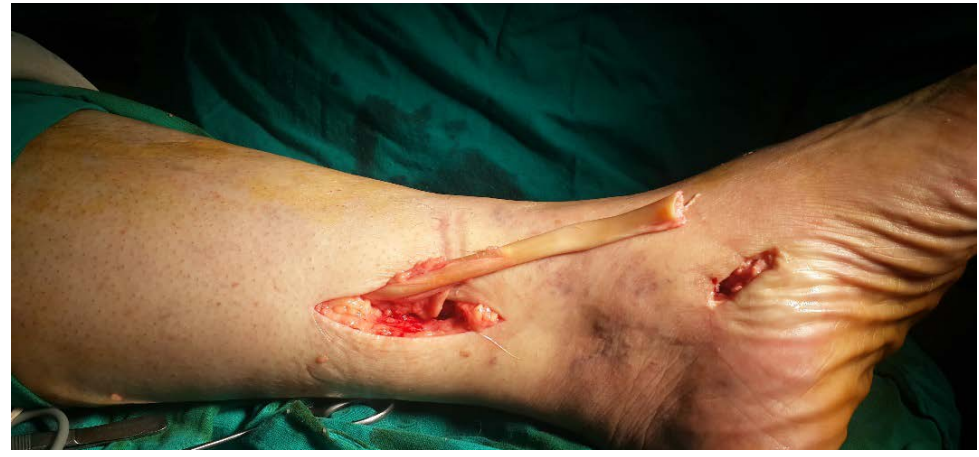

Figure 2. Harvesting Tibialis posterior tendon after division near its insertion.

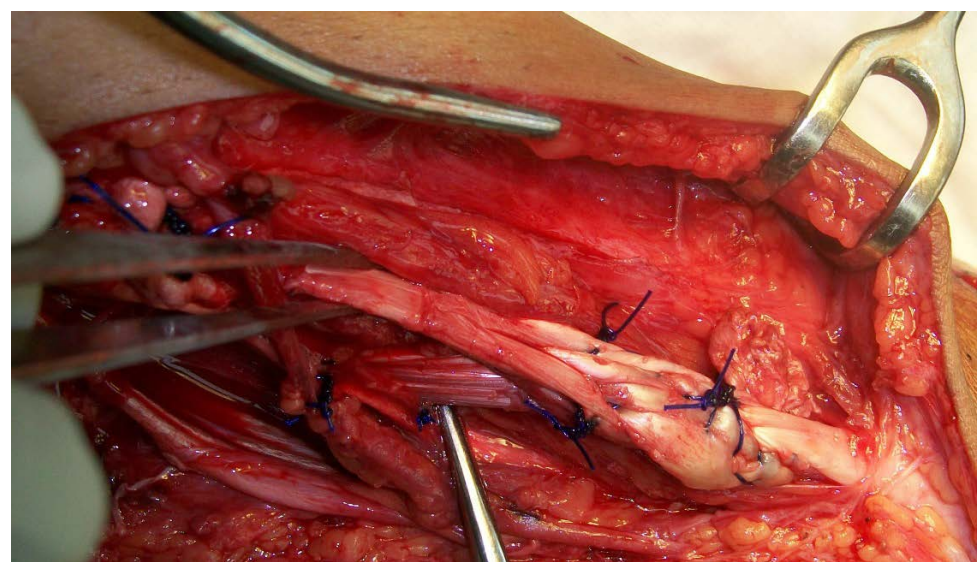

Figure 3. Transfer of tibialis posterior tendon to the tendons of the anterior compartment muscles.

\subsection{Post-Operative Measures}

All of our patients were put in a plaster cast for four weeks postoperatively. After the fourth week, the cast haves were removed to evaluate healing. Moreover, non-loading rehabilitation settings were commenced for all our patients. Full weight bearing exercises were allowed after 6 weeks.

\subsection{Outcome}

Patient outcome was evaluated by the medical research council score (MRC score), as well as assessing patient maximum ability to run and walk. The follow up period ranged from sex months to one year. Figure $4 \&$ Figure 5 show the preoperative and postoperative conditions of two of our cases.

\subsection{Statistical Analysis}

The collected data were coded, processed and analyzed using the SPSS (Statistical Package for Social Sciences) version 22 for Windows ${ }^{\circledast}$ (SPSS Inc, Chicago, IL, USA). Qualitative data was presented as number (frequency) and Percent. Quantitative data was tested for normality by Kolmogorov-Smirnov test and was expressed as median (range). 


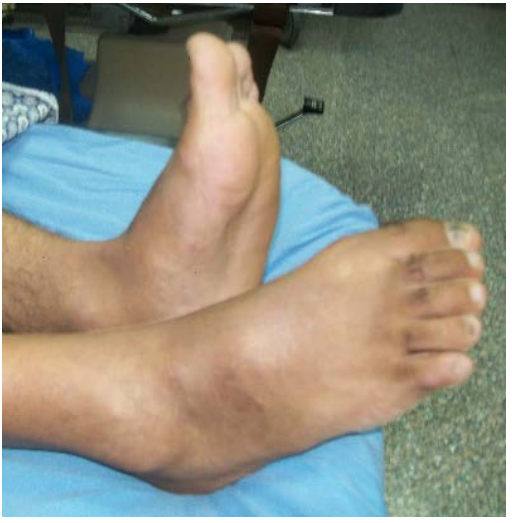

(a)

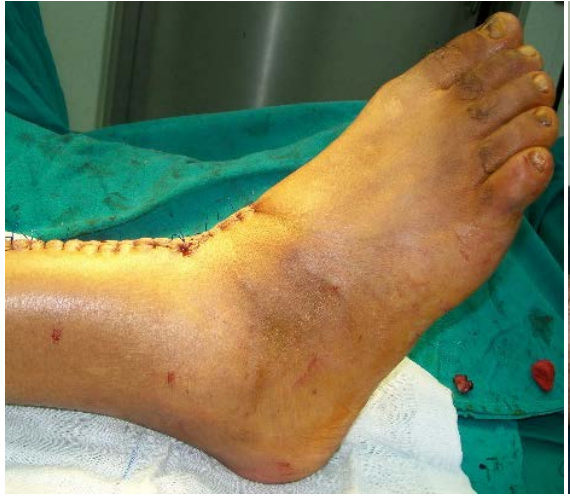

(b)

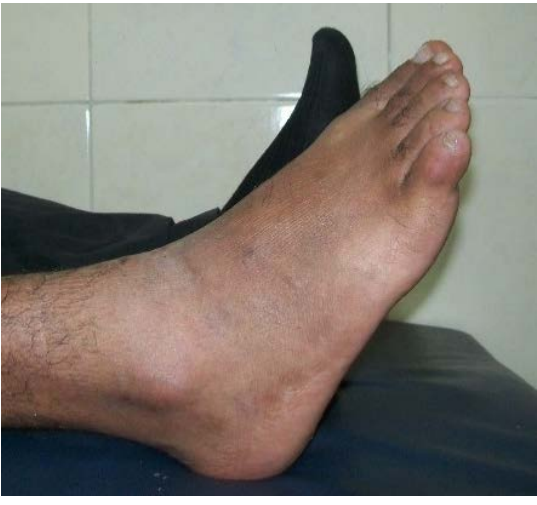

(c)

Figure 4. (a) Preoperative foot drop; (b) Intraoperative correction; (c) Four months follow up.

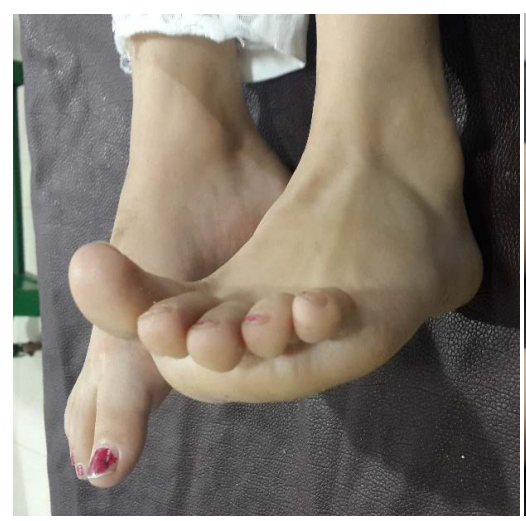

(a)

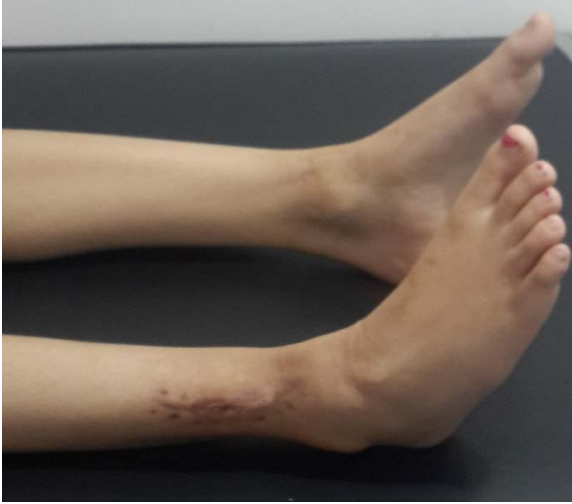

(b)

Figure 5. (a) Preoperative foot drop; (b) Sex months follow up.

\section{Results}

We included a total of 26 patients with their ages ranging between 6 and 58 years. Sixteen males were included (61.54\%), while the rest were females (38.46\%). Fourteen cases (53.85\%) had the nerve injured on the left side, whereas the remaining cases had the right side affected. Seventeen cases (65.38\%) had previous surgery for repair of this injury. The median time between the in- 
jury and our surgical intervention was about 3 years (range 1 - 6 years).

Regarding the mode of injury, the commonest type encountered in our study was injury by a sharp object that was reported in 11 cases $(42.3 \%)$, followed by blunt trauma that was reported in 7 cases $(26.92 \%)$. Knee dislocation was responsible for this complication in 4 cases (15.38\%). Iatrogenic nerve injury was present in two of our study cases (7.7\%). Nerve tumour and bony fracture were responsible for nerve injury in the remaining two cases; one for each.

Most of our patients ( 22 cases - 84.61\%) had satisfactory outcome, three patients $(11.54 \%)$ showed fair improvement, but only one patient (3.84\%) showed no improvement on active dorsiflexion. Regarding complications, superficial surgical site infection was encountered in two cases (7.69\%) which was treated by antibiotics and frequent dressing for two to three weeks. Deep venous thrombosis (DVT) occurred in one case (3.84\%) which was improved on medical treatment and patient received anticoagulants for sex months. As summarized in Table 2.

Table 2. Clinical data and results.

\begin{tabular}{|c|c|}
\hline Variable & Data \\
\hline Age (year) & $42(6-58)$ \\
\hline \multicolumn{2}{|l|}{ Sex } \\
\hline -Male & $16(61.54 \%)$ \\
\hline -Female & $10(38.46 \%)$ \\
\hline \multicolumn{2}{|l|}{ Affected side } \\
\hline -Left & $14(53.85 \%)$ \\
\hline -Right & $12(46.15 \%)$ \\
\hline \multicolumn{2}{|l|}{ Mode of injury } \\
\hline -Sharp trauma & $11(42.3 \%)$ \\
\hline -Blunt trauma & $7(26.92 \%)$ \\
\hline -Knee dislocation & $4(15.38 \%)$ \\
\hline -Iatrogenic injury & $2(7.7 \%)$ \\
\hline -Nerve tumour & $1(3.84 \%)$ \\
\hline -Bony fracture & $1(3.84 \%)$ \\
\hline $\begin{array}{c}\text { Time between injury and intervention } \\
\text { (year) }\end{array}$ & $3(1-6)$ \\
\hline Previous surgeries & $17(65.38 \%)$ \\
\hline \multicolumn{2}{|l|}{ Outcome (MRC score) } \\
\hline$-\mathrm{I}$ & $1(3.84 \%)$ \\
\hline$-\mathrm{II}$ & $0(0 \%)$ \\
\hline -III & $3(11.54 \%)$ \\
\hline$-\mathrm{IV}$ & $22(84.61 \%)$ \\
\hline$-\mathrm{V}$ & $0(0 \%)$ \\
\hline \multicolumn{2}{|l|}{ Patient maximum activity } \\
\hline -Running & $20(76.92 \%)$ \\
\hline -Walking & $26(100 \%)$ \\
\hline \multicolumn{2}{|l|}{ Complications } \\
\hline -Surgical site infection & $2(7.7 \%)$ \\
\hline -Deep vein thrombosis & $1(3.84 \%)$ \\
\hline
\end{tabular}




\section{Discussion}

In knee dislocations and other sharp injuries, nerve repair and tendon transfer have a good outcome whereas if different traumatic mechanisms were applied to the nerve (like gunshot or crush injuries), the recovery is described to be poor. That can be explained by vasa nervorum damage as well as muscle necrosis associated with such injuries [16].

The application of tendon transfer in the management of CPN injury has many advantages; it restores or reinforces the lost functions leading to improvement of the functional deficit, it provides neutralization of the opposing forces, and finally, it enables the patient to get rid of orthosis as gait stability is restored [17] [18].

For CPN palsy, foot dorsiflexion, supination, hallux and toe dorsiflexion, correction of equinovarus deformity, and avoiding high steppage gait should be the aim of the tendon transfer and that transfer would be more effective if it is dynamic in nature [19] [20]. Some surgeons recommended that slight or moderate tension should be created between the transposed muscle and the sutured tendon to enhance the post-operative outcome. Others stated that even suturing should be at high tension with the foot held at $90^{\circ}$ [8].

Terminal bone fixation of the transferred tendon does not allow the surgeon to set the muscle tension, which can have repercussions on the movement amplitude in the future because of the active nature of the transfer. The Pulvertaft suture technique has the same shortcomings [8] [21]. Still other techniques use a circumtibial transfer route, which can lead to residual foot varus if the posterior tibialis only is transferred [7] [22].

In this study, we included 26 patients with foot drop due to common peroneal nerve injury aiming to assess the efficacy of tibialis posterior tendon transfer procedure in the management of that neurological condition.

We included 16 males (61.54\%) and 10 females (38.46\%) in our study. The left leg was affected more in this study (53.85\% vs. $46.15 \%$ for the right leg). Previous attempts for repair were reported in 17 cases (65.38\%). Moreover, the median age of our included cases was 42 years ( 6 - 58 years).

In another study handling the same perspective, 16 cases were included with a mean age of 27 years (range 16 - 51 years). The majority of them were males (14 cases-87.5\%). The left leg was affected in 9 cases (56.25\%), while the right leg was affected in 7 cases (43.75\%). All of the included cases has undergone previous nerve repair (9 graft repair and 7 with 1ry repair) [7].

We reported that the interval time between the injury and time of tendon transfer was about 36 months, while other study reported a mean interval time of 26.7 months (range 7 - 192 months) before tendon transfer [7].

The most common incriminating factor in our study was sharp trauma (11 cases-42.3\%), followed by blunt trauma (7 cases-26.92\%). Dislocation of the knee was reported in 4 cases (15.38\%) while iatrogenic injury was encountered in 2 cases $(7.7 \%)$. Both nerve tumour and bony fracture were reported in two 
cases, one case for each cause.

Another study was conducted to evaluate the efficacy of combined nerve repair and tendon transfer in the management of such nerve injury. A total of 39 cases were included. The most common reported incriminating cause was knee dislocation (20 cases-51.28\%) followed by sharp injuries ( 9 cases-23.07\%). Iatrogenic injuries were reported in 4 cases (10.25\%) while compound crush fractures and gunshot injuries occurred in 3 cases (7.69\%) for each [16].

The results of the previously mentioned study that was conducted by Ferraresi and his associates revealed that good outcomes were obtained in 28 cases (71.79\%) while fair outcomes were reported in 7 cases $(17.94 \%)$. Poor outcomes were also reported in 4 cases (10.25\%) [16].

The outcome of tibialis posterior tendon transfer has been evaluated using different methods. In other studies, both the Stanmore classification and Carayon's criteria were used. The Carayon's classification is based mainly on the degree of active dorsiflexion. On the other hand, the Stanmore system is a more detailed classification that assess dorsiflexion in addition to the functional aspects of drop foot treatment, like pain, need for orthosis or special shoes, restriction of daily activities, muscle power, and foot posture. [7].

In our study, we used the medical research council score (MRC score), as well as assessing patient maximum ability to run and walk. Based on that score, 22 cases $(84.61 \%)$ had good outcomes while 3 cases $(11.54 \%)$ had fair outcomes. On the other hand, only one case (3.84\%) showed no response. At the end of our study, 20 cases $(76.92 \%)$ were able to run, while all cases (100\%) were able to walk.

Another study that assessed the tibialis posterior transfer also reported that the patient outcome was excellent in 10 cases $(62.5 \%)$, while good outcome was reported in 4 cases $(25 \%)$. Fair and poor outcomes were reported in only one case for each (6.25\%) [7].

Others concluded that tibialis posterior tendon transfers as a group produced $83 \%$ excellent or good results in terms of patient satisfaction with the outcome of surgery. It can therefore be recommended to patients who would prefer to discard an ankle-foot orthosis. The results are likely to be more successful if the nerve lesion causing the drop foot was at the common peroneal level rather than at the sciatic level and in men aged less than 30 years [20].

In our study, we reported that surgical site infection has occurred in two cases, but they were superficial and resolved with frequent dressing and antibiotics administration. The incidence of DVT that occurred in one case is a complication of the plaster cast that may render patient mobilization.

\section{Conclusion}

In conclusion, satisfactory results can be achieved for patients with foot drop due to $\mathrm{CPN}$ injury via tibialis posterior tendon transfer to the anterior compartment muscles. Moreover, this technique is simple, straight forward, and allows early adjustment of foot deformity and gait disability. 


\section{Conflicts of Interest}

The authors declare no conflicts of interest regarding the publication of this paper.

\section{References}

[1] Berry, H. and Richardson, P.M. (1976) Common Peroneal Nerve Palsy: A Clinical and Electrophysiological Review. Journal of Neurology, Neurosurgery and Psychiatry, 39, 1162-1171. https://doi.org/10.1136/jnnp.39.12.1162

[2] Tomaino, M., Day, C., Papageorgiou, C., Harner, C. and Fu, F.H. (2000) Peroneal Nerve Palsy Following Knee Dislocation: Pathoanatomy and Implications for Treatment. Knee Surgery, Sports Traumatology, Arthroscopy, 8, 163-165. https://doi.org/10.1007/s001670050208

[3] Hove, L.M. and Nilsen, P.T. (1998) Posterior Tibial Tendon Transfer for Drop-Foot. 20 Cases Followed for 1 - 5 Years. Acta Orthopaedica Scandinavica, 69, 608-610. https://doi.org/10.3109/17453679808999265

[4] Carayon, A., Bourrel, P., Bourges, M. and Touzé, M. (1967) Dual Transfer of the Posterior Tibial and Flexor Digitorum Longus Tendons for Drop Foot: Report of Thirty-One Cases. The Journal of Bone and Joint Surgery. American Volume, 49, 144-148. https://doi.org/10.2106/00004623-196749010-00013

[5] Wiesseman, G.J. (1981) Tendon Transfers for Peripheral Nerve Injuries of the Lower Extremity. The Orthopedic Clinics of North America, 12, 459-467.

[6] Terzis, J.K. and Saunders, W. (1987) Microreconstruction of Nerve Injuries. Journal of Pediatric Orthopaedics, 7, 484. https://doi.org/10.1097/01241398-198707000-00022

[7] Özkan, T., Tuncer, S., Ozturk, K., Aydin, A. and Ozkan, S. (2009) Tibialis Posterior Tendon Transfer for Persistent Drop Foot after Peroneal Nerve Repair. Journal of Reconstructive Microsurgery, 25, 157-164. https://doi.org/10.1055/s-0028-1103502

[8] Vigasio, A., Marcoccio, I., Patelli, A., Mattiuzzo, V. and Prestini, G. (2008) New Tendon Transfer for Correction of Drop-Foot in Common Peroneal Nerve Palsy. Clinical Orthopaedics and Related Research, 466, 1454-1466. https://doi.org/10.1007/s11999-008-0249-9

[9] Grauwin, M.Y., Wavreille, G. and Fontaine, C. (2015) Double Tendon Transfer for Correction of Drop-Foot. Orthopaedics and Traumatology: Surgery and Research, 101, 115-118. https://doi.org/10.1016/j.otsr.2014.12.005

[10] Codivilla, A. (1899) Sui trapianti tendinei nella practica ortopedica. Archivio di Ortopedia, 16, 225-250.

[11] Ober, F.R. (1933) Tendon Transplantation in the Lower Extremity. The New England Journal of Medicine, 209, 52-59. https://doi.org/10.1056/NEJM193307132090202

[12] Brand, P. and Selvapadian A. (1960) Tranfer of the Tibialis Posterior in Footdrop Deformities. Indian Journal of Surgery, 21, 157.

[13] Fritschi, E.P. and Brand, P.W. (1957) The Place of Reconstructive Surgery in the Prevention of Foot Ulceration in Leprosy. International journal of Leprosy, 25, 1-8.

[14] Watkins, M.B., Jones, J.B., Ryder Jr., C.T. and Brown Jr., T.H. (1954) Transplantation of the Posterior Tibial Tendon. The Journal of Bone \& Joint Surgery, 36, 1181-1189. https://doi.org/10.2106/00004623-195436060-00007

[15] Lipscomb, P.R. and Sanchez, J.J. (1961) Anterior Transplantation of the Posterior Tibial Tendon for Persistent Palsy of the Common Peroneal Nerve. The Journal of Bone \& Joint Surgery, 43, 60-66. 
https://doi.org/10.2106/00004623-196143010-00003

[16] Ferraresi, S., Garozzo, D. and Buffatti, P. (2003) Common Peroneal Nerve Injuries: Results with One-Stage Nerve Repair and Tendon Transfer. Neurosurgical Review, 26, 175-179. https://doi.org/10.1007/s10143-002-0247-4

[17] Mulier, T., Moens, P., Molenaers, G., Spaepen, D., Dereymaeker, G. and Fabry, G. (1995) Split Posterior Tibial Tendon Transfer through the Interosseus Membrane in Spastic Equinovarus Deformity. Foot and Ankle International, 16, 754-759. https://doi.org/10.1177/107110079501601203

[18] Wood, M. (1991) Peripheral Nerve Injuries to the Lower Extremity. Operative Nerve Repair and Reconstruction. JB Lippincott, Philadelphia, 489-504.

[19] De Marchi, F., Malerba, F., Alfieri, U.M., Ferrarin, M. and Rabuffetti, M. (2000) Tibialis Posterior Tendon Transfer through the Interosseal Membrane in Paralysis of the Common Peroneal Nerve. Foot and Ankle Surgery, 6, 19-25.

https://doi.org/10.1046/j.1460-9584.2000.00184.x

[20] Yeap, J.S., Birch, R. and Singh, D. (2001) Long-Term Results of Tibialis Posterior Tendon Transfer for Drop-Foot. International Orthopaedics, 25, 114-118. https://doi.org/10.1007/s002640100229

[21] Tomeno, B., Anract, P. and Vinh, T. (1998) Transfert du muscle tibial postérieur au dos du pied: Un procédé original de fixation du transplant. Revue de Chirurgie Orthopédique et Réparatrice de I Appareil Moteur, 84, 194-196.

[22] Bari, M., Islam, A. and Haque, A. (1996) Surgical Reconstruction of Leprotic Foot-Drop. Leprosy Review, 67, 200-202.

https://doi.org/10.5935/0305-7518.19960020 